\title{
Recurrent Mycosis Fungoides and Sezary Syndrome
}

National Cancer Institute

\section{Source}

National Cancer Institute. Recurrent Mycosis Fungoides and Sezary Syndrome. NCI

Thesaurus. Code C115439.

The reemergence of mycosis fungoides/Sezary syndrome after a period of remission. 